Article

\title{
Summer and Winter Effect of Innovative Cool Roof Tiles on the Dynamic Thermal Behavior of Buildings
}

\author{
Anna Laura Pisello *, Federico Rossi and Franco Cotana \\ CIRIAF (Interuniversity Research Center on Pollution and Environment "Mauro Felli"), \\ Department of Engineering, University of Perugia, Italy, via Duranti 63, Perugia 06125, Italy; \\ E-Mails: federico.rossi@unipg.it (F.R.); cotana@crbnet.it (F.C.) \\ * Author to whom correspondence should be addressed; E-Mail: pisello@crbnet.it; \\ Tel.: +39-075-585-3796; Fax: +39-075-515-3321.
}

Received: 30 January 2014; in revised form: 27 March 2014 / Accepted: 9 April 2014 / Published: 14 April 2014

\begin{abstract}
Cool roofs represent an acknowledged passive cooling technique to reduce building energy consumption for cooling and to mitigate urban heat island effects. This paper concerns the evaluation of the dynamic effect of new cool roof clay tiles on building thermal performance in summer and winter conditions. To this end, these properties have been analyzed on traditional roof brick tiles through an indoor and outdoor two-year long continuous monitoring campaign set up in a residential building located in central Italy. The analysis and the cooperation with industrial companies producing brick tiles and reflective coatings allowed the production of a new tile with notable "cool roof" properties through the traditional industrial manufacturing path of such tiles. Notable results show that during summer the high reflection tiles are able to decrease the average external roof surface temperature by more than $10{ }^{\circ} \mathrm{C}$ and the indoor operative temperature by more than $3{ }^{\circ} \mathrm{C}$. During winter the average external surface temperature is lower with high reflection tiles by about $1{ }^{\circ} \mathrm{C}$. Singular optic-thermal phenomena are registered while evaluating the dynamics of the cool roof effect. Interesting findings show how the sloped cool roof application could suggest further considerations about the dynamic effect of cool roofs.
\end{abstract}

Keywords: cool roof; passive cooling; solar reflectance; energy efficiency in buildings; continuous monitoring; cool clay tiles; residential building 


\section{Introduction}

Given the increasing energy prices and the large amount of energy consumption imputable to the construction sector (about $42 \%$ of electric power consumption and $15.3 \%$ of greenhouse gas emissions in Europe [1,2]), research on innovative energy technologies [3] and passive solutions for improving the energy efficiency of buildings has become a strategic environmental and economic issue. In particular, cooling energy consumption attributable to the residential sector is registering a growing trend [4] all over the world, rising worldwide concerns about the consequent environmental impact and the problem of summer peak electric loads [5].

In this field highly reflective building envelopes could represent an effective passive solution for reducing air-conditioning requirement in buildings [6]. In fact the main properties of a cool roof consist of high solar reflectivity and high thermal emissivity. These roofs are typically light in color and, thanks to these features, they are able to absorb less radiation, reducing the envelope overheating and consequently the building cooling load. Given these features, cool roof techniques have already been acknowledged as valid ways for: (a) reducing peak electricity demand and energy requirements for cooling in buildings [7]; (b) mitigating the Urban Heat Island and urban canyoning phenomena [8,9] and improving the livability at a mesoscale level; and (c) inducing a negative radiative forcing corresponding to $\mathrm{CO}_{2}$ equivalent emission offsetting [10,11]. Additionally, more recent research efforts concern high reflection surfaces' environmental benefits both from a global climate and local climate point of view $[12,13]$. For example in a large chaotic environment, where urban heat island phenomenon heavily impacts buildings' energy requirements, the direct $\mathrm{CO}_{2}$ emissions' reduction associated to the decrease of buildings' cooling consumptions was estimated at about $11 \mathrm{~kg} \mathrm{CO} / \mathrm{m}^{2}$ of flat roof area from [14]. Focusing on the direct benefits of cool roof on building thermal performance, Akbari and coauthors in [15] estimated the cooling saving for commercial buildings located in California through measured data integrated with calibrated simulations. They found important energy saving ranges for cooling, i.e., $1.5-7.4 \mathrm{kWh} /\left(\mathrm{m}^{2} \cdot\right.$ year $)$ in all the climate regions in California, produced by cool roof retrofit applications. An important research [16] analyzed the effect of envelope's absorbance decrease in residential buildings in Jordan through dynamic simulation. They found relevant results in terms of total energy load decrease especially for not insulated envelopes, i.e., $32 \%$ and $47 \%$ in the considered two locations in Jordan for the not insulated case, and $26 \%$ and $32 \%$ for insulated envelopes. Their results also showed that roof reflectivity has a huge impact on heating and cooling loads, and on the contrary the vertical wall reflectivity impact is almost negligible. Following the dynamic simulation approach they also found that in Jordan an important global energy saving can be achieved using highly reflective roofs coupled with good insulation, especially for optimizing winter performance too. Adopting a similar approach, Bathia and coauthors in [17] studied the impact of cool roofs on year-round energy requirement for heating and cooling in different climates in India, through a calibrated dynamic simulation using DesignBuilder (DesignBuilder Software Ltd, Stroud, Gloucs, UK), a simulation program that uses EnergyPlus (U.S. Department of Energy, Washington, DC, USA) as its simulation engine. They found that the cool roof strategy has a great impact in the warm and humid climatic zones of India. They also compared the energy saving potential with the financial payback period of the investment associated to the application of this technology. Thus their results showed that the payback time, such as the energy effectiveness, varies from 3 years in Mumbai 
to 6.7 years in Shillong, where the energy saving is just on the order of $3.16 \%$ for the floor next to the roof.

In an Italian context, as specified in [18], buildings' energy consumption corresponds to the $45 \%$ of the total energy national requirement. Therefore, large energy reductions could be achieved by controlling the energy performance of buildings' thermal equipment for cooling [19], by cutting down the sprawling diffusion of low-cost/low-efficiency systems in Italy. In fact, in the last few years these cooling systems have been installed in many residential buildings often without any thermal insulation. The Italian built environment [18] consists of about 26.5 million dwellings of which more than $66 \%$ were built before any energy efficiency law proclamation (1973). Therefore, almost all these buildings are not provided with any insulation panels or high efficiency strategies for reducing cooling and heating requirements. To solve this environmental, energy and economic issue, during the last few years increasing attention has also been paid in Italy in order to improve buildings' thermal performance. However most of the policy attention was focused on the optimization of winter energy performance, such as in France [19], especially by increasing building envelope insulation prescriptions for both new buildings and retrofits [20]. Even if Italy occupies a relatively small territory, climate conditions are largely variable along the country's territory, therefore effective strategies for improving buildings' energy performance in summer conditions are also required [21]. In particular, the indiscriminate diffusion of highly insulated envelope technologies, has brought large winter benefits coupled with summer penalties. In fact the European policy effort is pretty much focused on the first of these phenomena. In particular, D'Orazio and coauthors in [22] showed how over-insulation could produce important overheating effects through in-field monitoring of several roof typologies under typical summer Mediterranean climatological conditions. This insulation increase is also able to produce a permeability decrease that reduces the effect of important passive cooling strategies, such as natural ventilation through the envelope technologies.

\section{Motivation and Objective}

Given the importance of the energy and environmental issue related to existing buildings as explained above, the study of innovative, low-cost, technically simple to produce [23] and passive effective techniques for improving buildings' energy efficiency represents a huge research constraint, especially in the Mediterranean area [24]. As previously mentioned, the European Directive concerning the Energy Performance of Buildings [25] established procedures and technologies for saving energy during winter, but just qualitative suggestions are reported in Italian regulations for summer. Therefore, an important research effort is aimed at optimizing this effect [26].

In the context of experimental research about cool roof applications, important improvements have been carried out with the purpose of developing cool versions of the clay tiles that cover the large majority of roofs in Southern European countries [27]. This research starts from the previous work about the in-field monitoring of a residential building while the year-round thermal assessment of cool tiles is described [28].

Building upon this previous study, this contribution is aimed at studying the effect of albedo optimization of roof brick tiles as an effective strategy to improve the free-running indoor thermal dynamics, considering both winter and summer climate conditions, with particular focus on the 
analysis of effects during the course of the day. The study consists of a brief description of the experiment and a deep analysis of the daily and monthly reflectance profile, of the thermal behavior of roof and of the indoor environment. Specific attention is paid to the peculiar geometry of the traditional Italian sloped roof, and its impact on the thermal performance of the building in free-floating conditions through the analysis of two-year long continuously monitored data.

\section{Choice of the Case Study}

In order to assess the impact of roof reflectance on the thermal behavior of the roof and of the building attic, an experimental campaign was carried out concerning a residential building built in 1973 located in Perugia, in central Italy. As outlined, we chose that residential building for several strategic reasons such as: (i) representative construction characteristics; (ii) climate context; (iii) occupants' schedules; (iv) its use of traditional roof technology.

(i) The case study adequately represents a common traditional Italian residential building. In fact this architectural and technical typology represents more than the $66 \%$ of the residential buildings' stock in Italy [18]. Thus the investigation and the proposal of effective low-cost passive strategies for improving the energy efficiency of this kind of existing buildings could be important for a large part of the Italian, and Mediterranean in general, built environment.

(ii) The climate context of Perugia, Italy, is characterized by a temperate climate, where cool roof technologies could be useful during the summer but where it is actually crucial to investigate the impact of the heating penalties that could arise during winter. The two-year long experimental campaign allows us to compare traditional and cool roof elements through year-round application and continuous monitoring of both of them.

(iii) The entire attic floor of the selected building performs in free-running conditions and in fact the entire attic floor of the case study building is unoccupied. This fact allows us to study the thermal free-running indoor behavior without other effects caused by occupants' particular attitudes and the related internal gains-losses, that could highly impact the thermal measurements [29]. Thus the monitored attic is characterized by a constant ventilation rate (no usually open windows or mechanical systems). Also the internal gains due to occupants' activities are negligible, given that the only person who usually accesses the monitored area is one of the authors that controls the monitoring system once a month, for about $20 \mathrm{~min}$. In this way we are able to continuously identify cool roofs' effectiveness with respect to the real unaffected monitored weather conditions, without assuming any hypothesis related to indoor operational schedules and occupants' activities [30].

(iv) The roof covering with brick tiles is representative of a very large portion of the Italian built environment (more than $90 \%$ of residential buildings). Thinking about cool roof strategy as a fruitful solution for optimizing thermal comfort conditions and energy saving in Italian new and existing buildings, necessarily implies taking into account buildings' standard roof construction practices. That is the main reason why, according to several industrial companies, we decided to optimize the cool roof properties of the traditional brick tile. 
The case study of this research, as outlined before, consists of a single-family residential building in Perugia, Italy, built in 1973 (Figure 1). It represents a common masonry house typology in Italy [18] which architecture is shown in Figure 1 [28]. Technical features of the opaque and transparent envelope are reported in [31] where external walls' and roof's transmittance values were experimentally measured in-field. Climate conditions of the location are reported in Table 1.

Figure 1. Residential building representing the case study. West front (a) and South-West front (b).
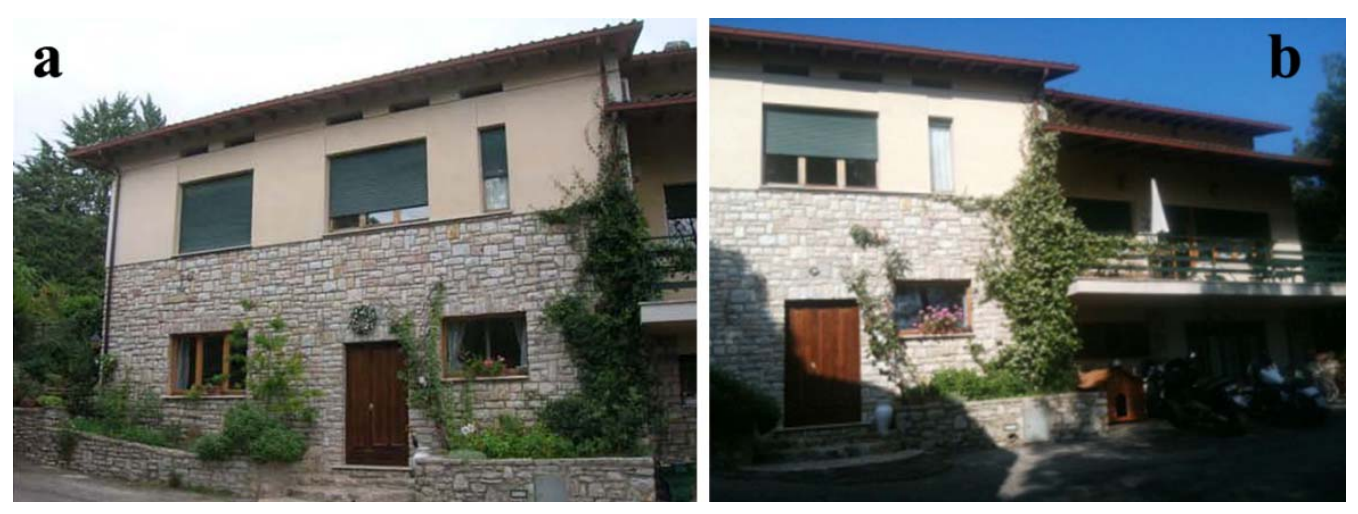

Table 1. Climate conditions and positioning of the case study *.

\begin{tabular}{|c|c|c|c|c|c|c|c|c|c|c|c|c|c|c|c|c|c|}
\hline \multirow{2}{*}{ Parameter } & \multicolumn{12}{|c|}{ Months } & \multicolumn{4}{|c|}{ Seasons } & \multirow{2}{*}{ Annual } \\
\hline & Jan & Feb & Mar & Apr & May & Jun & Jul & Aug & Sep & Oct & Nov & Dec & Win & Spr & Sum & Fall & \\
\hline$T_{\text {max-average }}\left({ }^{\circ} \mathrm{C}\right)$ & 6.9 & 8.4 & 11.7 & 15.7 & 20.4 & 24.9 & 28.2 & 28.0 & 23.6 & 17.6 & 12.0 & 8.1 & 7.8 & 15.9 & 27 & 17.7 & 17.1 \\
\hline$T_{\text {min-average }}\left({ }^{\circ} \mathrm{C}\right)$ & 0.5 & 2.0 & 4.1 & 7.1 & 10.9 & 14.7 & 17.3 & 17.4 & 14.6 & 10.4 & 6.2 & 2.9 & 1.8 & 7.4 & 16.5 & 10.4 & 9 \\
\hline $\begin{array}{l}\text { Rainfall rate } \\
\quad(\mathrm{mm})\end{array}$ & 61 & 60 & 70 & 79 & 76 & 64 & 39 & 45 & 76 & 102 & 103 & 75 & 196 & 225 & 148 & 281 & 850 \\
\hline $\begin{array}{c}\text { Rainy days } \\
(\geq 1 \mathrm{~mm})\end{array}$ & 8 & 8 & 9 & 10 & 10 & 7 & 4 & 4 & 7 & 9 & 10 & 10 & 26 & 29 & 15 & 26 & 96 \\
\hline $\begin{array}{c}\text { Sunshine } \\
\text { duration (h/day) }\end{array}$ & 3.1 & 3.7 & 5.0 & 5.4 & 6.7 & 7.7 & 9.6 & 8.4 & 6.9 & 6.3 & 3.7 & 2.8 & 3.2 & 5.7 & 8.6 & 5.6 & 5.8 \\
\hline
\end{tabular}

* Location: Perugia, Italy. Latitude: $43^{\circ} 06^{\prime}$; Longitude: $12^{\circ} 18^{\prime}$; Elevation above sea level: $522 \mathrm{~m}$.

\section{Experimental Campaign}

Given the purposes of this research, the building was equipped with two connected monitoring stations: the first one is located outside and positioned $4 \mathrm{~m}$ away from the house at a height of $5 \mathrm{~m}$, and the second one was positioned within the attic [28]. The weather station represents the master station (MS) of the experimental apparatus and it is continuously linked to the slave system (SS) represented by the indoor monitoring station. The whole experimental apparatus is able to register all the parameters every $20 \mathrm{~s}$. Therefore, we collect the average, maximum, minimum, and the standard deviation values of all these parameters every $10 \mathrm{~min}$. Finally we use these 6 per hour values to study the effect of the prototyped cool roof tile. The meteorological station (MS) monitors: (i) relative humidity; (ii) dry bulb air temperature; (iii) wind main direction and velocity; (iv) global radiation arriving to the roof and reflected by the roof through an albedometer installed over the roof, with radiometers positioned on a horizontal plane; (v) direct solar radiation on an horizontal plane; (vi) external roof surface temperature; (vii) sunshine daily duration. The indoor microclimate station (SS) 
monitors: (i) indoor relative humidity and (ii) air temperature; (iii) air velocity; (iv) black globe temperature (v) internal roof surface temperature and (vi) ceiling surface temperature.

The monitoring activity (still on-going) began in June 2010. During the entire first year of monitoring the house was in the Scenario "0" (S-0) configuration represented by the roof covered by old brown brick tiles. Therefore, during this first year we were able to characterize these tiles by investigation in laboratory. The first in-lab experimental campaign consisted of measuring the reflectance and the emissivity of the old tiles. Reflectance properties have been investigated by spectrophotometer following the procedures described in [31]. Emissivity measurements have been carried out by portable emissometer as described in [31] for both the measurement and the error assessment procedures. The base case tile was characterized by $19 \%$ of solar reflectance, against the optimized tile, characterized by $77 \%$ of solar reflectance. The emissivity values were the same for both the tiles, corresponding to $89 \%$ [28].

During the S-0 monitoring (June 2010-June 2011, Figure 2a), we cooperated with several industrial companies with the following scope: to design a brick tile able to optimize cool roof performance in terms of Solar Reflection Index, as specified in [32], considering both reflectivity and emissivity properties. In our opinion, to maximize the potential usefulness of this application, this tile should be produced using the same industrial procedure of traditional brick tiles, and thus have a similar cost of production and selling price, to be competitive within the market, since the beginning of the potential commercialization. In order to pursue this objective, we cooperated with both the company producing brick components and the company producing coatings for brick tiles to be applied as engobe. With a continuous follow-up process made by laboratory measurements and industrial consultation and feasibility investigation, we designed a highly reflective and high emissivity light colored tile, to be installed for the second year of the experimental campaign. The industrial procedure for producing this new tile is exactly the same as that of traditional tiles with engobe (Table 2). Therefore, the coating quality and its durability properties can be assumed to be the same of classic tiles covered by such a coating. In fact, the production procedure is the same as that of other commercialized tiles with esthetic surface effects, e.g., fake aged effect treatments. Both of the roof elements are produced through just one cooking cycle within industrial ovens, where the brick dries and the coating is able to anchor to the brick support. The two types of tiles determine the scenarios' characterization. Scenario " 0 " (S-0) is characterized by the dark tiles originally installed in the case study building, with a dark brown dark engobe, already on the market. The Scenario "1" (S-1, Figure 2b) is characterized by the optimized high reflectance elements. Therefore, after selecting the best performing tile in terms of reflectance (through in-lab optimization), we decided to produce these tiles to be installed in place of the dark traditional tiles. In fact, the plan consisted of monitoring the optimized building for another complete year (June 2011-June 2012), in order to compare the cool roof performance represented by Scenario " 1 " configuration with the previous Scenario " 0 ".

The final analysis consisted of the evaluation of the roof thermal behavior and the indoor free-running thermal trend with respect to the specific weather conditions in each scenario, in order to capture both daily and seasonal fluctuations. Therefore, after an entire year of Scenario " 0 " monitoring, and after selecting the best performing cool roof element produced by the industrial company with our guide, the second monitoring year began in June 2011 after installing the high reflectance tiles on the roof of the case study building. 
Table 2. Production process of traditional and prototyped tiles.

\begin{tabular}{|c|c|}
\hline Main phases & Main operations \\
\hline 1. Excavation of the clay & \\
\hline $\begin{array}{l}\text { 2. First manufacture of the clay, where there is a sort of } \\
\text { selection and eventually water is added to the material }\end{array}$ & \\
\hline 3. Molding of the tiles through extrusion and pressing & \\
\hline 4. Desiccation process & \\
\hline $\begin{array}{l}\text { 5. Characterization of the surface finishing, if different } \\
\text { from the natural red brick color, when also the white } \\
\text { reflecting durable coating has been applied }\end{array}$ & \\
\hline $\begin{array}{l}\text { 6. Cooking phase within specific tunnel-ovens that reach } \\
\text { a temperature of about } 1080{ }^{\circ} \mathrm{C} \text {, and where the tiles } \\
\text { stay for about } 40 \mathrm{~h} \text {. This phase determines most of the } \\
\text { durability resistance of the tiles }\end{array}$ & \\
\hline $\begin{array}{l}\text { 7. Packaging and storage making of the tiles, that remain } \\
\text { within the factory, before the shipping }\end{array}$ & \\
\hline
\end{tabular}

In order to study the impact of cool roof, we collected all the experimental data measured by the indoor and the outdoor stations for analyzing the results in terms of comparison between continuous weather conditions and the house thermal behavior. In this way we analyzed the house thermal performance with respect to the specific climate conditions of each period, without comparing directly S-0 and S-1 results, which data could be affected by large weather peculiarities between the first and the second monitoring year. Therefore, the S-0 data are referred to the period between June 2010 and June 2011. The S-1 data concerns the following year. In this way, we were able to compare winter and summer for investigating which is the impact of high reflectance tiles on the case study building. 
We organized the following data analysis in three main sections, each one concerning both summer benefits and winter penalties in the hottest and coldest month, respectively. Firstly, there is: (a) the assessment of the roof reflectance capability; secondly, we reported (b) the roof thermal performance, and thirdly, we dealt with (c) the assessment of the indoor environment. In this latter part we assessed cool roof potential for reducing the roof and the indoor environment overheating.

Figure 2. (a) Scenario 0 with original tiles compared to Scenario 1 configuration; (b) with reflective tiles.

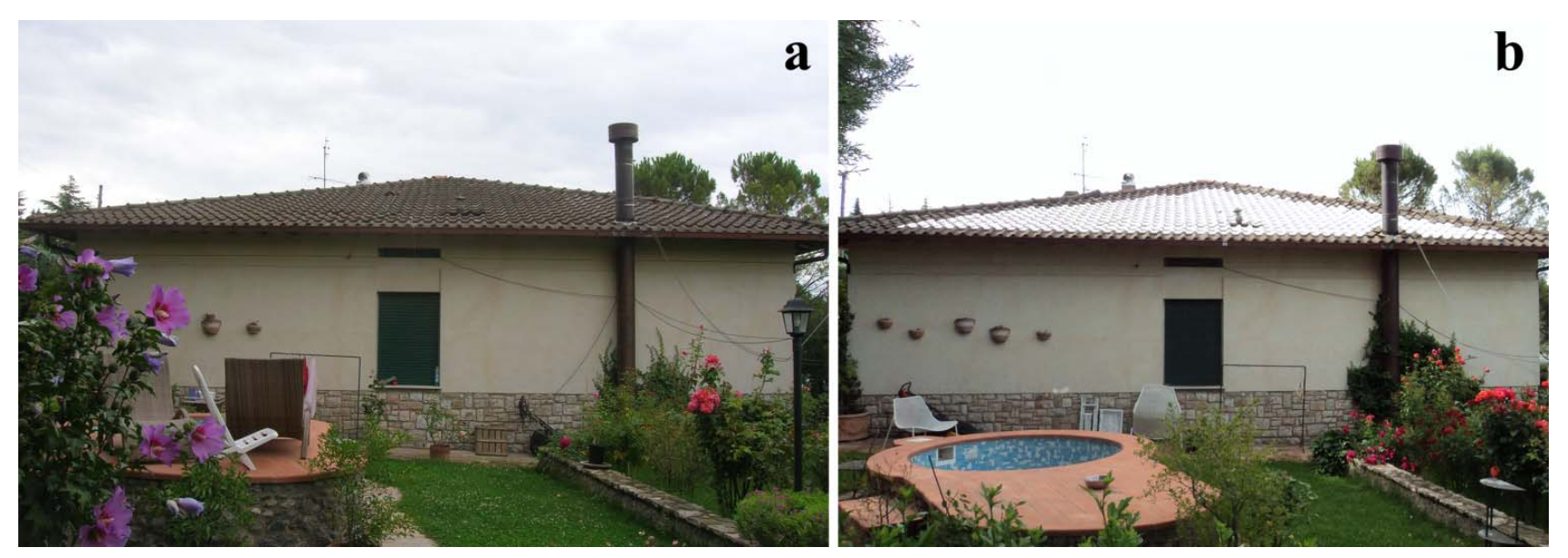

\section{Discussion of the Results}

The results of the continuous monitoring presented in this section basically concern: (i) the roof reflectance; (ii) the roof thermal behavior; (iii) the cool roof effect in the indoor thermal environment. We take into account the July-August two-month period for studying the summer conditions and the December-January two-month interval for winter, given the climatological features of the city. Particular attention is paid to the daily and seasonal fluctuations of the boundary conditions affecting the reflectance and thermal dynamics of the roof and the indoor environment.

\subsection{Roof Reflectance}

Results of the in-field continuous monitoring of the global radiation reflected by the roof show that the tile optimization and installation effectively increases the reflection capability of the S-1 brick tiles. Calculating the ratio between the reflected quote and the received quote of the global radiation, we find a reflectivity increase of $223 \%$ during summer months (July, August, 2010-2011) when the reflectance has the highest impact given the more important entity of solar radiation. The same ratio is around $162 \%$ in winter (December, January, 2011-2012). Therefore, we observe a predominant effect during sunny summer months with respect to a lower but not negligible effect during winter. Figure 3 represents the reflected global radiation versus the corresponding global radiation received by the roof. We compare the reflectance capability of each scenario, with respect to the irradiance monitored in each scenario, in order to avoid misleading conclusions due to different weather conditions in the two monitored periods. We find that these trends could be effectively represented by linear profiles: the coefficient of determination $R^{2}$ values are higher than $97 \%$ in summer and higher than $84 \%$ in winter, when there is a bigger results scattering. Comparing Scenario 0 and Scenario 1, we find that 
reflectance optimization is able to pick up the line slopes from 0.15 up to 0.50 in summer, and from 0.09 up to 0.28 in winter. Therefore, also in this case we observe a very high effect during July 2010-2011 (Figure 4a), and also a not negligible effect during January 2011-2012 (Figure 3b). The values of the line slopes during the analysed months comparing S-0 and S-1 confirm that, in terms of reflectance, summer effect is higher than the winter effect by about $20 \%$. Interesting consideration could be carried out by observing the higher dispersion of the measured values in winter.

Figure 3. Roof reflectance capability with respect to the global radiation of the location in (a) July and (b) January.

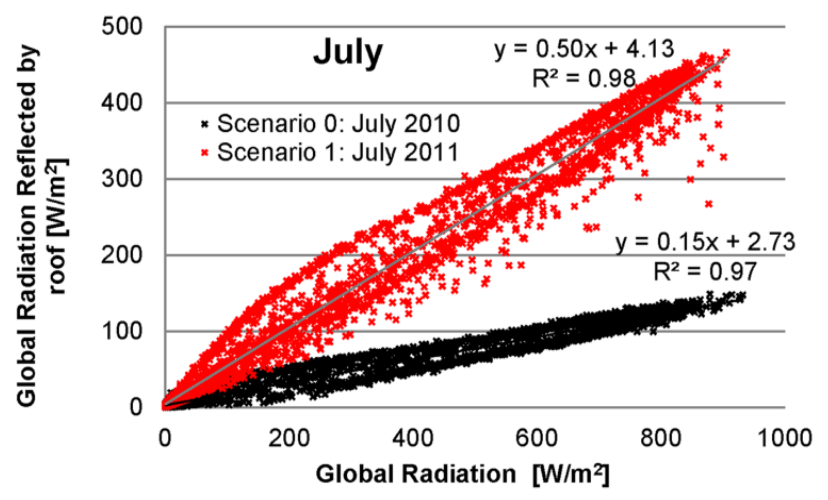

(a)

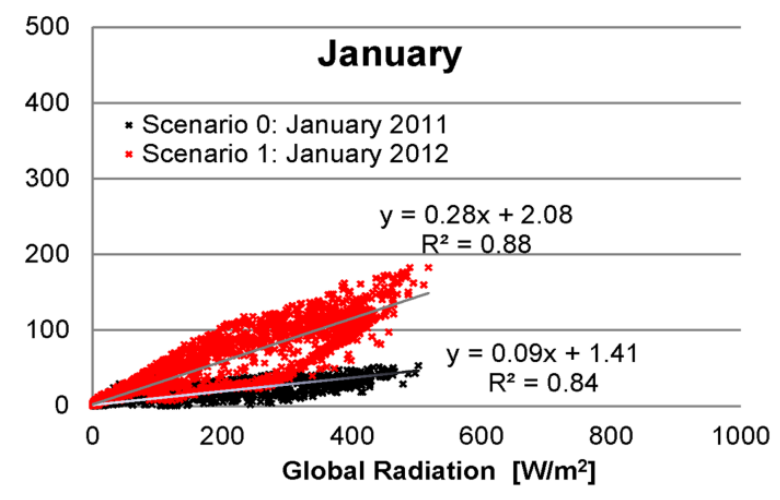

(b)

Given the sloped configuration of the cool roof, we can observe that the classic albedometer technique (double pyranometer upward and downward oriented on a horizontal plane, respectively) underestimates the solar reflected radiation when the sloped portion of the roof is not directly reached by sunbeams. Consistent results are also observed in summer, when the higher sun position contributes to reduce such a singular effect imputable to this uninvestigated sloped roof geometry. This phenomenon is able to produce a lower measured reflectance capability in the morning, when the roof slope is not reached by direct irradiation, since the characterized slope is North-West oriented. In such conditions, the downward oriented pyranometer views both the roof and the surrounding surfaces characterized by much lower solar reflectance. The presence of these objects, e.g., trees, affects the final measurement of the irradiance collected by the downward oriented pyranometer and it produces an overall underestimation of the reflectance capability of the prototyped roof.

Consistent results are reported in Figures $4 \mathrm{a}, \mathrm{b}$ where we represent the weekly trend of solar radiation received by roof (dotted lines) to compare S-0 and S-1 both in summer (July 2010-2011) and winter (January 2011-2012) weather conditions. We find that, besides previous considerations, the reflected radiation profile is highly dependent to the global radiation trend. Additionally, during sunny days in summer there is a more stable effect that is clearly attributable to S-1 tiles' capabilities. During winter, the radiation profiles are more jagged given the sunshine higher variability during the day, and the effect of tiles' reflectivity is a bit confused, given this global radiation trend.

The overall winter daily trend describes an effective reflectance capability increase, consistently with the previous considerations, but there is not a clear contribution imputable to the tiles effect. 
Figure 4. Global reflected radiation capability with respect to the outdoor temperature in (a) July and (b) January.

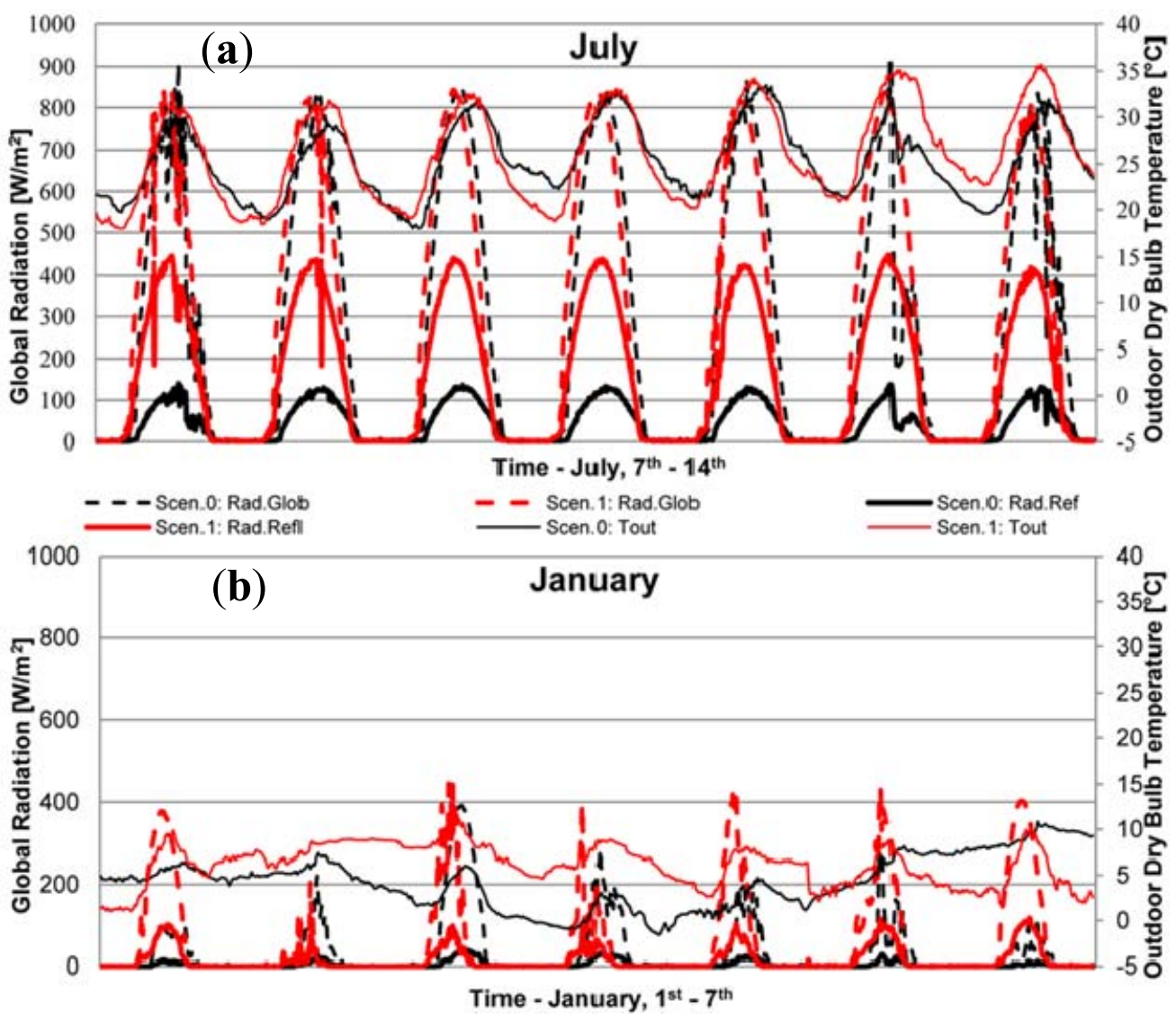

\subsection{Roof Thermal Behavior}

This section concerns the analysis of the roof thermal conditions during summer and winter with respect to the solar radiation collected through the continuous monitoring campaign. To this end we analyse the thermal profiles of entire weeks during the monitored months, reported in Figures 5a,b, where we can observe the hottest and the coldest months of the Italian location. Looking at the summer conditions in July, when we selected the most similar weather conditions to compare S- 0 and S-1, the results show how the reflective tiles can contribute to the decrease of the outside surface temperature of the roof. Scenario 0's results register roof external surface overheating by about $20{ }^{\circ} \mathrm{C}$ in peak conditions, while in Scenario 1's period the same peak values are just about $2-3{ }^{\circ} \mathrm{C}$ higher than the monitored outdoor dry bulb temperature.

A different phenomenon is observed in Figure 5b representing one week in January to describe the winter thermal behavior of the roof. Here we find that there is not the same evident phenomenon observed in summer. In fact the profiles of the roof external surface temperature are very much subject, both in terms of shape and values, to the outdoor air temperature of the location. The average difference between the outdoor temperature and the roof external surface temperature is about $0.7{ }^{\circ} \mathrm{C}$ for S-0 and $2.6{ }^{\circ} \mathrm{C}$ for S-1. For both these scenarios the surface external temperature of the roof is lower than the outdoor temperature on the monthly average calculation. 
Figure 5. Weekly trends of external temperature, surface roof temperature and standard deviation in July (a) and January (b).
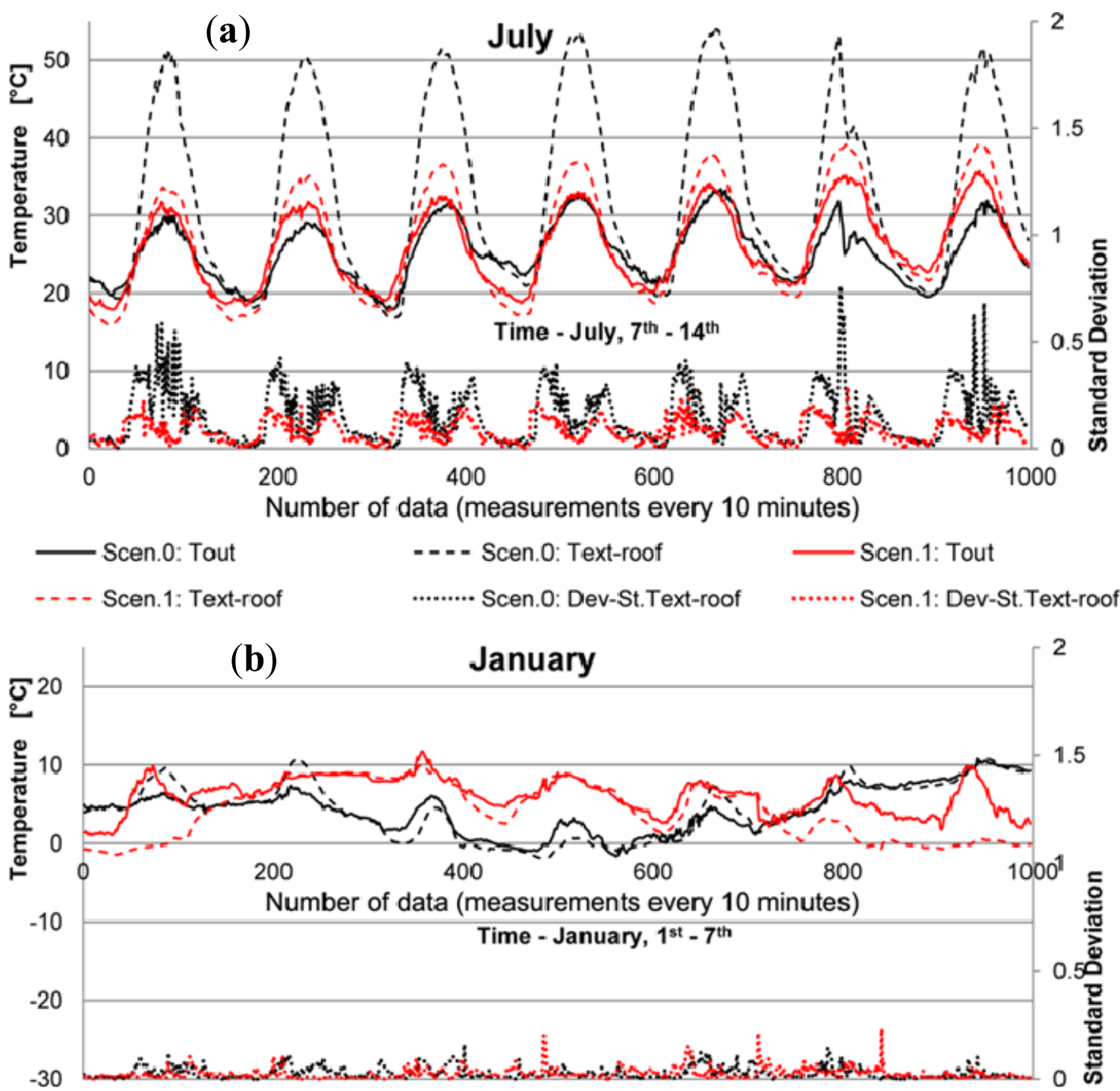

Considering the monitoring data reported in Figure 5a,b we also observe that, while small effects are registered at lower temperature (both in winter and summer during the night), larger effects are produced by the tile substitution to decrease the maximum thermal peaks close to noon. This element shows that the thermal profiles of S- 0 and S- 1 conditions are very similar during the night, i.e., for the lower section of the thermal profiles where both the outdoor air temperature and the surface temperatures of the roof are very close (the typical maximum difference is around $2{ }^{\circ} \mathrm{C}$ ).

Conversely, during the high section of the thermal profiles described in Figure 5a,b, the overheating phenomenon is always very much defeated in Scenario 1. In particular, during summer the overheating of the roof external surface with respect to the outdoor air temperature varies from about $20-25{ }^{\circ} \mathrm{C}$ during the two-month interval July-August 2010 of the S- 0 to about $2{ }^{\circ} \mathrm{C}$ of the S-1 conditions in the same period of the following year (July-August 2011).

Interesting observations are found through linear regression to evaluate roof overheating (calculated by the difference between the external surface temperature of the roof and the outdoor dry bulb temperature) versus the global radiation of the monitored location at the same times. Figure $6 a, b$ 
represent the cases of July and January, respectively, where there is the comparison between S-0 and $\mathrm{S}-1$. We decided to represent the linear regression in the figure, to basically describe the overall effect, even if the low correlation coefficient values do not properly describe the relation. In July we find that the reflecting tiles are able to reduce the line slope by about 5 -fold with respect to the S- 0 case and also the y-intercept is reduced by $1.34{ }^{\circ} \mathrm{C}$ from the S-0 to S-1 results. These trends also show the biggest effect of the tiles reflectance when the global radiation is higher in the considered location. Therefore, for sunny places and basically in hot climate conditions, with high solar radiation values, the roof reflectance increases its impact in reducing the roof temperature. The thermal flux entering the building through the roof is lower too. Repeating the same analysis also in other periods during the course of the year, in particular in the statistically coldest month that is January (Figure 6b), we find that the impact of S-1 implementation is absolutely lower than during summer. Therefore in winter the impact of the roof reflectance is always lower than $3{ }^{\circ} \mathrm{C}$, while in summer, with high radiation conditions, the impact is around $20{ }^{\circ} \mathrm{C}$ in terms of roof overheating reduction. Considering in this section just the thermal behavior of the roof, we find that cool roof application has larger benefits for lowering the roof overheating phenomenon in summer while roof reflectance is not able to greatly impact the roof thermal behavior in winter, given the lower radiation intensity. This result concerning the roof behavior shows the smaller winter penalties related to the cool roof implementation, with respect to the summer evident benefits. Furthermore, both in summer and winter, the night period shows larger similarities between S-0 and S-1 conditions, meaning that cool roof impact is basically more effective in higher global radiation contexts. The particular hysteresis loop shape of the relation we observe in Figure 6a is consistent with the results observed in Figure 3, and it represents the specific daily trend of the overheating path with respect to global solar radiation. We can see that also the overheating is affected by the sloped roof geometry, as was observed in Figure 3. In particular, when the solar radiation does not directly impact the monitored slope, i.e., in the morning, its overheating reduction is also lower than the phenomenon observed in the afternoon. In winter analyses (Figure 6b) this trend is not clearly visible, given the low effect of the global radiation for determining roof overheating and the lower sun height. On the contrary in summer, we can identify the ante-meridiem path (lower hysteresis beam) and the post-meridiem path (higher hysteresis beam). This decreasing path represents in particular the roof overheating trend happening in the afternoon when we can observe that the tiles tend to maintain their highest temperature even when the global radiation begins to decrease. During the ante-meridiem period, the overheating growing trend is characterized by a higher slope level. This singular behavior is directly imputable to the specific geometry of the roof slope, which is North-West oriented.

An interesting further observation results from focusing on the last part of the daily hysteretic cycle described by the overheating path versus the global radiation. In summer (Figure 6a), before the cool roof tile implementation, Scenario 0 was characterized by important overheating values, even after the sunset, which mainly shows the effect of the roof's thermal inertia to store the heat collected during the sunny hours of the day. The same phenomenon is not observable in Scenario 1 conditions, where the cool roof tile is able to reflect the incoming solar radiation without producing a sort of delayed overheating of the roof. 
Figure 6. Roof overheating with respect to the global radiation of the location in (a) July and (b)January.

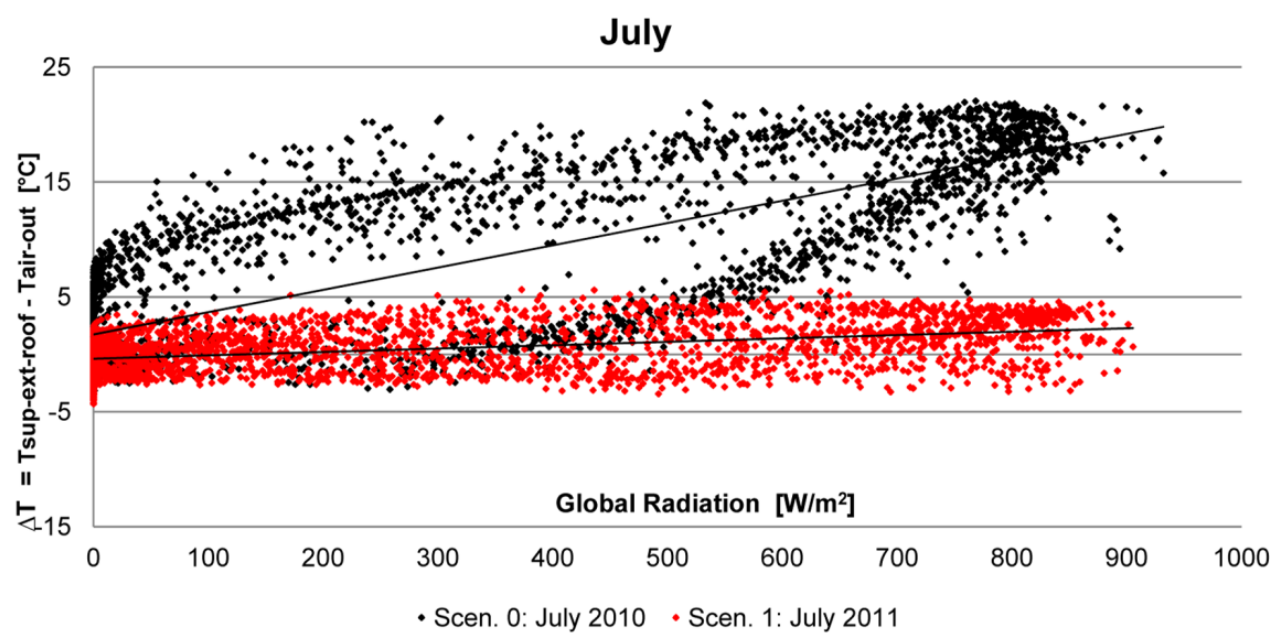

(a)

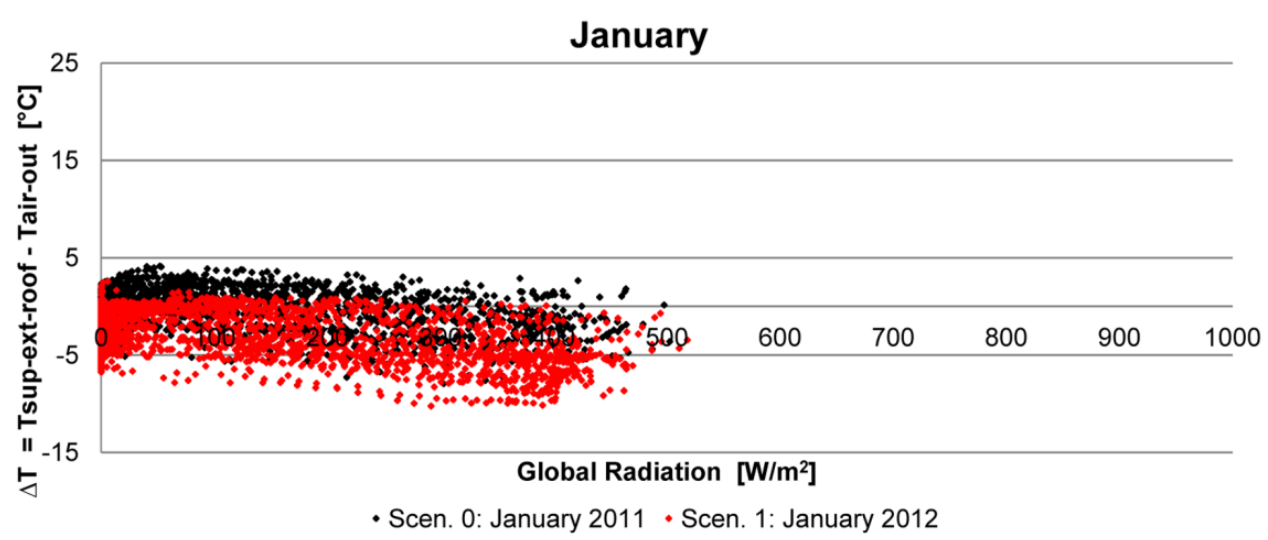

(b)

Consistent with previous analyses, Figure 6 shows that during winter the tiles reflectance is not able to produce the same important effect in terms of roof overheating. The same hysteresis shape describing the daily trend basically becomes an almost linear path around the null value of the temperature difference represented in the $y$-axis. These peculiar trends show two main time variations: firstly, seasonal variability demonstrates well the cool roof's capability to have the highest effect when most required. Secondly, the particular roof slope orientation determines the observed hysteresis loop profile of the overheating daily path. The observed phenomenon suggests that cool tiles in sloped roofs could be selectively applied in specific orientations, in order to reduce the thermal gain entering the roof in different time intervals during the course of the day and the year.

\subsection{Indoor Thermal Behavior}

Analysing the continuous monitoring data concerning the indoor thermal environment adjacent to the roof, here we assess the effect of the high reflectance tiles on the indoor operative temperature, also considering global and reflected radiation as input parameters for studying the attic thermal environment both in summer and winter conditions. Figure 7 shows the attic overheating (calculated through the difference between the operative indoor temperature and the outdoor dry bulb temperature, 
both experimentally monitored) versus the global radiation measured by the pyranometer upward oriented and located over the roof. This monitored parameter, i.e., solar radiation measured by the upward oriented pyranometer over the roof, is considered to drive the thermal behavior of the roof and of the attic as well, since the high impact of the proposed tile is related to high solar radiation conditions, as previously observed. We find that during summer, e.g., in the July assessment represented in Figure $7 \mathrm{a}$, the reflective tiles are able to shift the indoor average overheating by about $3{ }^{\circ} \mathrm{C}$ in July and $2{ }^{\circ} \mathrm{C}$ in August. Additionally, the observed reflective tiles effect is pretty linear with respect to the global radiation. This means that the cool roof prototype is able to decrease the attic overheating during the course of the day, even without solar radiation, i.e., after the sunset, even if slightly larger effect is registered during sunny hours. Therefore, the observed cool roof effect is massive in summer sunny hours but, thanks to the contribution of materials' thermal inertia, the same cool roof effect is notable, even during the night. In winter, we observe that the average impact of the Scenario-1 implementation is almost negligible, especially in the coldest month of the year (January) reported in Figure $7 \mathrm{~b}$, where the indoor thermal behavior of the two scenarios is actually comparable. December results show that the penalties in terms of attic thermal behavior are around $0.6{ }^{\circ} \mathrm{C}$ during night and around $1.5^{\circ} \mathrm{C}$ in high global radiation conditions, i.e., about $400 \mathrm{~W} / \mathrm{m}^{2}$. Consistent results are found if we analyse indoor operative temperature of the attic versus outdoor dry bulb temperature, to make the results mutually independent with respect to the weather difference between the two non-contemporary scenarios (Figure 8). The graphs show how the cool roof potentiality to reduce indoor operative temperature is clearly higher with higher outdoor temperature. In fact, the maximum effect is observed for outdoor temperature higher than $30^{\circ} \mathrm{C}$ for both the scenarios, when the indoor operative temperature decreases of more than $4{ }^{\circ} \mathrm{C}$. Additionally, the typical daily overheating path of the attic is consistent with the roof thermal behavior observed in Figure 6.

Figure 7. Monthly assessment of the indoor environment overheating with respect to the global radiation of the location in (a) July and (b) January.

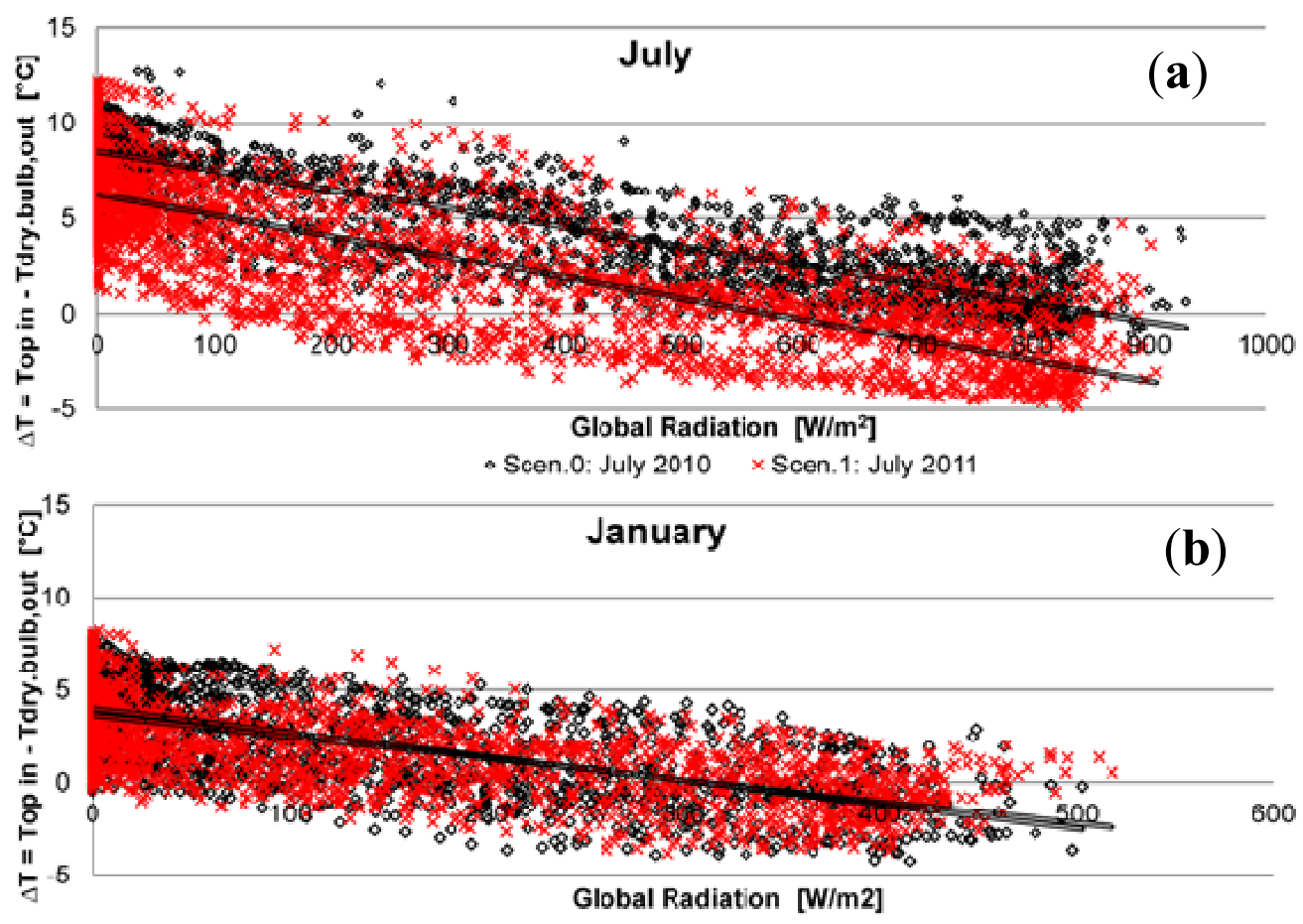


Figure 8. Monthly assessment of the indoor operative temperature versus outdoor dry bulb temperature of the location in (a) July and (b) January.

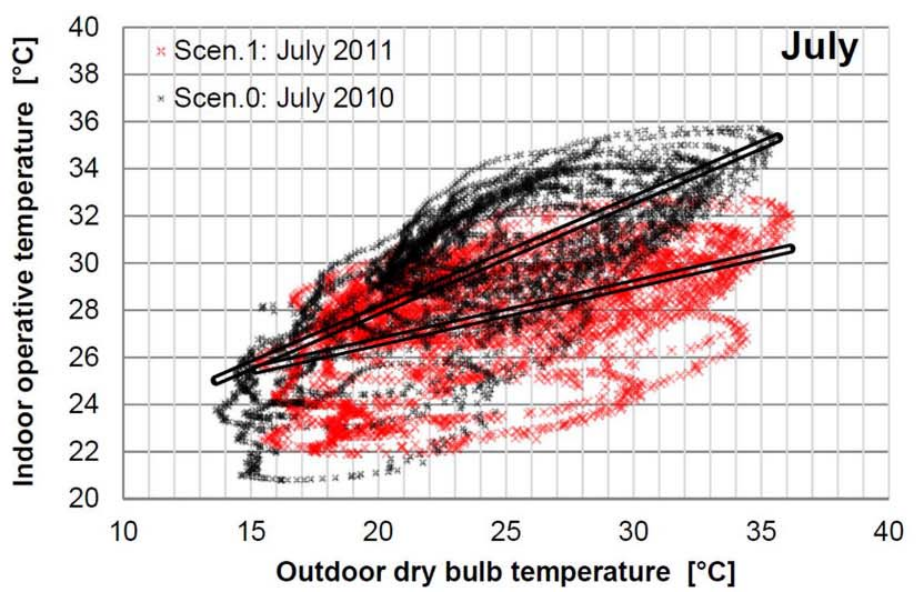

(a)

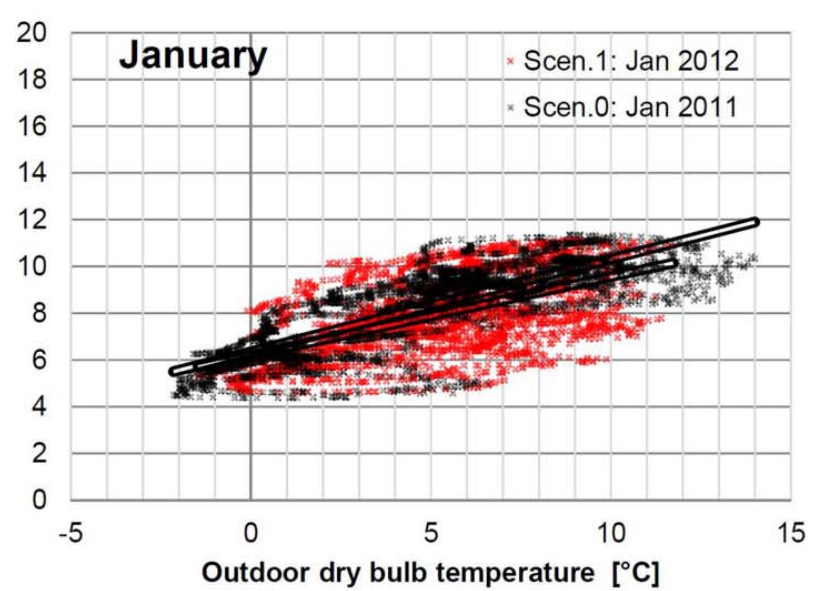

(b)

\section{Limitations and Future Developments}

Even if the choice of the building has been carried out by following the guidelines described in the previous sections of the paper, the results are related to this specific case study. The house in this study is a very common and representative architectural prototype of Italian residential buildings. Therefore, the future development of the research will consist of the energy modelling and calibrated-validated dynamic simulation of the whole building, aimed at extending the validity of these results to other case studies.

The white tiles have not been installed over all the building roof. In fact, the white tiles cover an surface of about $80 \mathrm{~m}^{2}$, where the experimental monitoring systems are installed (both the indoor and the outdoor station). Given the architectural layout of the building and of the indoor attic space, that is completely separated by the other thermal zones, we assumed that the cool roof implementation in the monitored area is representative of the whole attic.

The presence of a non-insulated roof presents a twofold implication. Firstly, it is representative of the Italian traditional built environment; secondly, it emphasizes the cool roof effect with respect to a high insulated envelope, both in terms of summer benefits and winter penalties. The evaluation of this case study basically could also be strategic for the possibility to consider this strategy as a simple and low-cost energy retrofit.

The proposed innovative brick tiles have been produced through the same industrial process of the other existing tiles and the actual color is basically light beige-white. In this view, the coating durability is supposed to be the same of other commercialized tiles with classic engobes. Further developments of this research will concern the in-field analysis of the surface optic-energy properties of such tiles over the course of time. This prototype represents the maximization of the effect of this kind of cool roof. We are also developing light colored tiles, to discover their cool roof potential, reducing at the same time, their aesthetic impact for the overall house architecture [33], for application in historic buildings. 


\section{Conclusions}

A continuous monitoring of indoor and outdoor environmental parameters on a real residential building in central Italy has been carried out to study the effect of roof brick tiles' reflectance both on the roof thermal behavior and on the indoor thermal performance of a free running thermal zone of the house. The analysis was aimed at evaluating the effective cooling benefits during summer days, and the winter penalties, in order to determine if simple cool roof strategies could be applied also in humid subtropical climate (Köppen climate classification) similar to much of Northern Italy.

The study shows how this kind of roof element optimization in terms of reflectance and emissivity could decrease the roof external temperature and to reduce also the attic overheating, especially when it is mostly required, that is when the sloped roof is directly impacted by sunbeams. In particular, the analysis consisted of the study of the threefold cool roof effect: firstly, the roof effective reflectivity profile; secondly, the roof thermal behavior; thirdly, the indoor thermal performance of the free running attic.

The first analysis showed a reflectivity increase up to $223 \%$ in July and August, and up to $167 \%$ in December and January. The particular trends also demonstrated that when the irradiance is high (more than $600 \mathrm{~kW} / \mathrm{m}^{2}$ in summer), the roof reflectance triplicates. However in winter this effect was evident as well, but the global radiation reflected by roof had more disaggregated trends and final lower increase levels. The assessment of the roof thermal behavior showed an average reduction of external roof peak temperature by $15-20{ }^{\circ} \mathrm{C}$ in summer, when the roof temperature profile became very close to the outdoor thermal profile during the day in high reflective roof configuration. During the night this difference is almost negligible, showing how the roof temperature trend is very dependent on the external weather conditions in terms of global radiation and dry bulb temperature of the location. Important findings for winter analysis showed that, i.e., in January, the roof thermal behavior is very much related to the outdoor weather conditions and the roof reflectance is actually not able to modify the roof thermal performance. Interesting observations were carried out by analysing the daily path described by: (i) the reflected radiation versus the irradiance and (ii) the roof overheating versus the irradiance. These parameters describe hysteresis loops showing the effect of the sloped roof geometry in the case (i) and the combined effect of roof geometry and thermal inertia in case (ii).

Important findings were observed by assessing the indoor thermal behavior. The overheating assessment showed that the cool roof implementation was able to decrease the indoor operative temperature with respect to the outdoor dry bulb temperature of about $3{ }^{\circ} \mathrm{C}$ in summer on the average. On the contrary, in winter this phenomenon was almost negligible: in particular in January the average indoor overheating with respect to the outdoor global radiation of both the configurations (with cool roof and without cool roof) registered comparable trends.

The proposed methodology described in this paper consisted of an experimental continuous monitoring campaign of a real building before and after implementing cool roof brick tiles followed by the fundamental data analysis, aimed at quantifying benefits and penalties of cool roof through daily and year-round assessment. The study showed that cool roof strategies constitute effective solutions for optimizing indoor thermal performance in summer, while winter penalties of the same configurations are very much lower than summer benefits, in terms of indoor thermal behavior of the free running attic, also in climate contexts with high seasonal thermal variability. Important 
preliminary findings are also shown with the purpose of investigating the peculiar behavior of sloped cool roofs, which thermal performance is very well captured through long-term continuous monitoring campaign such as the one presented in this paper.

\section{Acknowledgments}

The authors' acknowledgements are due to: (i) H2CU (Honors Center of Italian Universities) for supporting the cooperation among the authors; (ii) the Biomass Research Centre for supporting the first experimental campaign set up; (iii) Fornaci Briziarelli Marsciano industrial company for their help in the production phase of the innovative roof elements.

\section{Author Contributions}

This work builds upon the work carried out by Anna Laura Pisello in her PhD thesis. Anna Laura Pisello is the principal investigator of this research. Franco Cotana, as her scientific tutor in the PhD school, supported Anna Laura Pisello's research in terms of both scientific and technical expertise. Federico Rossi contributed in the data analysis.

\section{Conflicts of Interest}

The authors declare no conflict of interest.

\section{References}

1. Buonomano, A.; Palombo, A. Building energy performance analysis by an in-house developed dynamic simulation code: An investigation for different case studies. Appl. Energy 2014, 113, 788-807.

2. International Energy Agency. Strategies and Opportunities to 2050. In Transition to Sustainable Buildings; International Energy Agency: Paris, France, 2013.

3. Gentili, P.L.; Penconi, M.; Ortica, F.; Cotana, F.; Rossi, F.; Elisei, F. Synergistic effects in hydrogen production through water sonophotolysis catalyzed by new $\mathrm{La}_{2 x} \mathrm{Ga}_{2 y} \operatorname{In} 2_{(1-x-y)} \mathrm{O}_{3}$ solid solutions. Int. J. Hydrog. Energy 2009, 34, 9042-9049.

4. Synnefa, A.; Santamouris, M.; Akbari, H. Estimating the effect of using cool coatings on energy loads and thermal comfort in residential buildings in various climatic conditions. Energy Build. 2007, 39, 1167-1174.

5. Berardi, U.; GhaffarianHoseini, A.; GhaffarianHoseini, A. State-of-the-art analysis of the environmental benefits of green roofs. Appl. Energy 2014, 113, 788-807.

6. Pisello, A.L.; Santamouris, M.; Cotana, F. Active cool roof effect: Impact of cool roofs on cooling system efficiency. Adv. Build. Energy Res. 2013, 7, 209-221.

7. Akbari, H. Measured energy savings from the application of reflective roofs in two small non-residential buildings. Energy 2003, 28, 953-967. 
8. Gaffin, S.R.; Imhoff, M.; Rosenzweig, C.; Khanbilvardi, R.; Pasqualini, A.; Kong, A.Y.Y.; Grillo, D.; Freed, A.; Hillel, D.; Hartung, E. Bright is the new blackmulti-year performance of high-albedo roofs in an urban climate. Environ. Res. Lett. 2012, 7, doi:10.1088/1748-9326/ 7/1/014029.

9. Bonamente, E.; Rossi, F.; Coccia, V.; Pisello, A.L.; Nicolini, A.; Castellani, B.; Cotana, F.; Filipponi, M.; Morini, E.; Santamouris, M. An energy-balanced analytic model for urban heat canyons: Comparison with experimental data. Adv. Build. Energy 2013, 7, 222-234.

10. Cotana, F.; Rossi, F.; Filipponi, M.; Coccia, V.; Pisello, A.L.; Bonamente, E.; Petrozzi, A.; Cavalaglio, G. Albedo control as an effective strategy to tackle Global Warming: A case study. In Proceedings of International Conference on Applied Energy, Pretoria, South Africa, 1-4 July 2014.

11. Menon, S.; Akbari, H.; Mahanama, S.; Sednev, I.; Levinson, R. Radiative forcing and temperature response to changes in urban albedos and associated $\mathrm{CO}_{2}$ offsets. Environ. Res. Lett. 2010, 5, 1-11.

12. Doya, M.; Bozonnet, E.; Allard, F. Experimental measurement of cool facades' performance in a dense urban environment. Energy Build. 2012, 55, 42-50.

13. Rossi, F.; Pisello, A.L.; Nicolini, A.; Filipponi, M.; Palombo, M. Analysis of retro-reflective surfaces for urban heat island mitigation: A new analytical model. Appl. Energy 2014, 114, 621-631.

14. Akbari, H.; Xu, T.; Taha, H.; Wray, C.; Sathaye, J.; Garg, V.; Tetali, S.; Babu, M.H.; Reddy, K.N. Using Cool Roofs to Reduce Energy Use, Greenhouse Gas Emissions, and Urban Heat-island Effects: Findings from an India Experiment; Lawrence Berkeley National Laboratory: Berkeley, CA, USA, 2011.

15. Akbari, H.; Levinson, R.; Rainer, L. Monitoring the energy-use effects of coolroofs on California commercial buildings. Energy Build. 2005, 37, 1007-1016.

16. Shariah, A.; Shalabi, B.; Rousan, A.; Tashtoush, B. Effects of absorptance of external surfaces on heating and cooling loads of residential buildings in Jordan. Energy Convers. Manag. 1997, 39, 273-284.

17. Bhatia, A.; Mathur, J.; Garg, V. Calibrated simulation for estimating energy savings by the use of cool roof in five Indian climatic zones. J. Renew. Sustain. Energy 2011, 3, 1-14.

18. Italian National Agency for New Technologies, Energy and Sustainable Economic Development (ENEA). Libro Bianco Energia-Ambiente-Edificio; ENEA: Rome, Italy, 2005. (In Italian)

19. Henze, G.P.; Felsmann, C.; Knabe, G. Evaluation of optimal control for active and passive buildingthermal storage. Int. J. Therm. Sci. 2004, 43, 173-183.

20. Dall'O', G.; Sarto, L.; Panza, A. Infrared screening of residential buildings for energy audit purposes: Results of a field test. Energies 2013, 6, 3859-3878.

21. Sadineni, S.B.; Madala, S.; Boehm, R.F. Passive building energy savings: A review of building envelope components. Renew. Sustain. Energy Rev. 2011, 15, 3617-3631.

22. D'Orazio, M.; di Perna, C.; di Giuseppe, E. The effects of roof covering on the thermal performance of highly insulated roofs in Mediterranean climates. Energy Build. 2010, 42, 1619-1627.

23. Xu, X.; Taylor, J.E.; Pisello, A.L. Network synergy effect: Establishing a synergy between building network and peer network energy conservation effects. Energy Build. 2014, 68, 312-320.

24. Santamouris, M.; Kolokotsa, D. Passive cooling dissipation techniques for buildings and other structures: The state of the art. Energy Build. 2013, 57, 74-94. 
25. Energy Efficiency: Energy Performance of Buildings. Available online: http://europa.eu/ legislation_summaries/other/127042_en.htm (accessed on 30 January 2014).

26. Corgnati, S.P.; Jarre, M. Radiant floor behavior in removing cooling loads from large glassed buildings. Lect. Notes Electr. Eng. 2014, 262, 243-250.

27. Libbra, A.; Tarozzi, L.; Muscio, A.; Corticelli, M.A. Spectral response data for development of cool coloured tile coverings. Opt. Laser Technol. 2011, 43, 394-400.

28. Pisello, A.L.; Cotana, F. The thermal effect of an innovative cool roof on residential buildings in Italy: Results from two years of continuous monitoring. Energy Build. 2014, 69, 154-164.

29. Hoes, P.; Hensen, J.L.M.; Loomans, M.G.L.C.; de Vries, B.; Bourgeois, D. User behavior in whole building simulation. Energy Build. 2009, 41, 295-302.

30. Pisello, A.L.; Bobker, M.; Cotana, F. A building energy efficiency optimization method by evaluating the effective thermal zones occupancy. Energies 2012, 5, 5257-5278.

31. Pisello, A.L.; Goretti, M.; Cotana, F. A method for assessing buildings' energy efficiency by dynamic simulation and experimental activity. Appl. Energy 2012, 97, 419-429.

32. Akbari, H.; Levinson, R. Evolution of cool-roof standards in the US. Adv. Build. Energy Res. 2008, 2, 1-32.

33. Pisello, A.L.; Cotana, F.; Nicolini, A.; Brinchi, L. Development of clay tile coatings for steep-sloped cool roofs. Energies 2013, 6, 3637-3653.

(C) 2014 by the authors; licensee MDPI, Basel, Switzerland. This article is an open access article distributed under the terms and conditions of the Creative Commons Attribution license (http://creativecommons.org/licenses/by/3.0/). 